\title{
Logical Soft Systems Methodology for Education Programme Development
}

\author{
Ho-Leung Tsoi \\ Caritas Francis Hsu College, Hong Kong
}

hltsoi@yahoo.com

\begin{abstract}
Business Information Systems education--such as majoring in Business Computing, E-Commerce and Business Computing, and Information Systems--is the basic foundation of all Information Systems professionals. So good planning of these programmes is an indispensable element in the development of computing disciplines. The traditional ways of planning an education programme are mainly based on understanding the goals and including appropriate teaching modules to fulfil the requirements. The major drawback of this development methodology is that the importance of different (though relevant) modules in the development process may be undermined. For instance, human and environmental factors are fundamental to planning an education programme and must be taken into account. Soft Systems Methodology (SSM) is a well-known model for information system design. This paper proposes to see an education programme as a system and adopts the soft systems concept to represent the design of the programme. Based on the soft systems concept, a new methodology, named Soft Systems Programme Planning Methodology (SSPPM), for programme planning is proposed to support designing and planning a new postsecondary programme. The SSPPM not only considers all relevant facets, but it also helps the school management to clarify the connectivity of the elements in the design of a programme.
\end{abstract}

Keywords: Software Systems Methodology (SSM), Information Systems, Action Research.

\section{Introduction}

Hong Kong is an important financial, commercial, and industrial centre in the Asia-Pacific region. The IT (Information Technology) and Business Computing (collectively called Business Information Systems (BIS)) have proliferated and been used extensively in both the private and public sectors of Hong Kong. The application of BIS has been considered an important factor in maintaining Hong Kong's position as one of the world's leading financial and commercial centres. Employers are demanding BIS professionals who are capable of managing the business aspects of BIS, for example, project and contract management, business analysis, and sales. BIS practitioners need to have a more rounded approach to work, that is, having technical expertise along with an understanding of how technology impacts on business. Many colleges and Univer-

Material published as part of this journal, either on-line or in print, is copyrighted by Informing Science. Permission to make digital or paper copy of part or all of these works for personal or classroom use is granted without fee provided that the copies are not made or distributed for profit or commercial advantage AND that copies 1) bear this notice in full and 2) give the full citation on the first page. It is permissible to abstract these works so long as credit is given. To copy in all other cases or to republish or to post on a server or to redistribute to lists requires specific permission from the publisher at Publisher@InformingScience.org sities in Hong Kong provide different courses in their curricula to provide knowledge of computer and information technology to their undergraduates and postgraduates. As society depends more and more on computers, 
there is an increasing demand for BIS professionals.

Recognising the importance of developing BIS human resources, the Hong Kong government has been investing substantially at all levels of education and training, especially on post-secondary education (Hong Kong Commerce, Industry and Technology Bureau 2001; "Way forward," 2001). Over the past few years, despite tight government finances caused by the financial crisis after 1997, the Hong Kong government has still continuously increased its investment in local education. The planned target is that, within 10 years, $60 \%$ of school leavers will have a chance to receive tertiary education. To achieve this policy objective, the Hong Kong government introduced a series of support measures for both students and providers of post-secondary programmes, such as introducing the "Associate Degree" (hereafter $\mathrm{AD}$ ). AD is a common recognised post-secondary qualification in North America. The Hong Kong government introduced and drew up a set of common descriptors of an $\mathrm{AD}$ and equivalent qualifications. It paved the way for the AD in Hong Kong to be internationally recognised. Moreover, the Hong Kong government also encourages several local education providers, private or government-funded Institutes, to launch new AD programmes or convert existing Higher Diploma programmes into AD courses in order to achieve their goal.

The project considered in this paper incorporated an action research approach and soft system methodology intervention. Section 2 of this paper overviews the processes and principles of Action Research. Section 3 of this paper introduces the Soft System Methodology and investigates the application of the Soft System Methodology in the design of an education programme. The methodology identifies rules that are suitable for programme planning. Section 4 summarises the research outcomes and discusses future work.

\section{Why Action Research?}

Generally, education and teaching are an applied discipline; such research needs to be relevant to practice. It is essential for ideas, principles, and methods developed in a research environment to be tested in practice. However, it is very difficult to get new approaches accepted and used in practice. As a result, many proposed methods are theoretically sound but unproven in practice. This research adopts the action research approach (Avison, Lau, Myes, \& Nielsen., 1999; Kemmis, 1980; Lewin, 1946) to bridge the gap between theory and practice. It enables researchers to become deeply involved with the processes that take place in an organisation.

Action research is an established research method in use in the social and medical sciences since the mid-twentieth century. The term "action research" was first proposed by Kurt Lewin (1946). He believes that social-psychological phenomena can be studied experimentally and the results are a huge impetus for scientific research. Rapoport (1970) identifies action research as a means of using research to address the practice problems of people and enable the researcher to develop applicable knowledge in the problem domain. The four basic elements for action research are: plan, act, observe, and reflect. Kemmis (1980) goes on to note that action research involves the application of tools and methods from the social and behavioural sciences to practical problems with dual intentions of improving the practice and contributing to theory and knowledge in the area being studied. Thus, Elden and Chisholm (1993) view action research as a form of problemcentred research that bridges the difference between theory and practice. It provides a synergistic solution to link organisational needs and academic research desires.

Action research combines theory and practice (researcher and practitioners) through change and reflection in a problematic situation. The researcher starts with conceptualising and particularising the problem. Several interventions and evaluations had been moving through. During and around the time of the intervention, actual data and pertinent observations are collected in vari- 
ous forms. If problems are identified, modification of the old strategies or new strategies is carried out until a sufficient understanding of the problem is achieved. Through an iterative process, researcher and practitioners act together on a particular cycle of activities including problem diagnosis, action intervention, and reflective learning (see Figure 1).

For action research to be successful, the organisation must be supportive of, and the processes being investigated must be conducive to, information sharing and learning. Actually, the researcher is not just an independent observer but also an active participant in the whole case study. The researcher and the practitioners are working together to test and refine the theories, algorithms, and methodologies. The researcher is not alone in gathering data for the research, as the other participants are also responsible for data collection. The sharing of data feeds into a learning process in which the researcher modifies their theories and the other participants modify their perceptions and ways of working. The major advantage of this arrangement is that it helps the researcher to overcome the problem of persuading practitioners to adopt new methodologies, methods, and techniques. Moreover, it shortens the gap between information systems academics and practitioners. The experiences gained in practice helps the researcher to develop and refine the theories, algorithms, and methodologies.

In summary, the adopted research approach provides a unique implementation and research context in which implementation, practice, and research reap benefits and inform one another. It can be regarded as a way of carrying out research and acting to change situations at the same time.

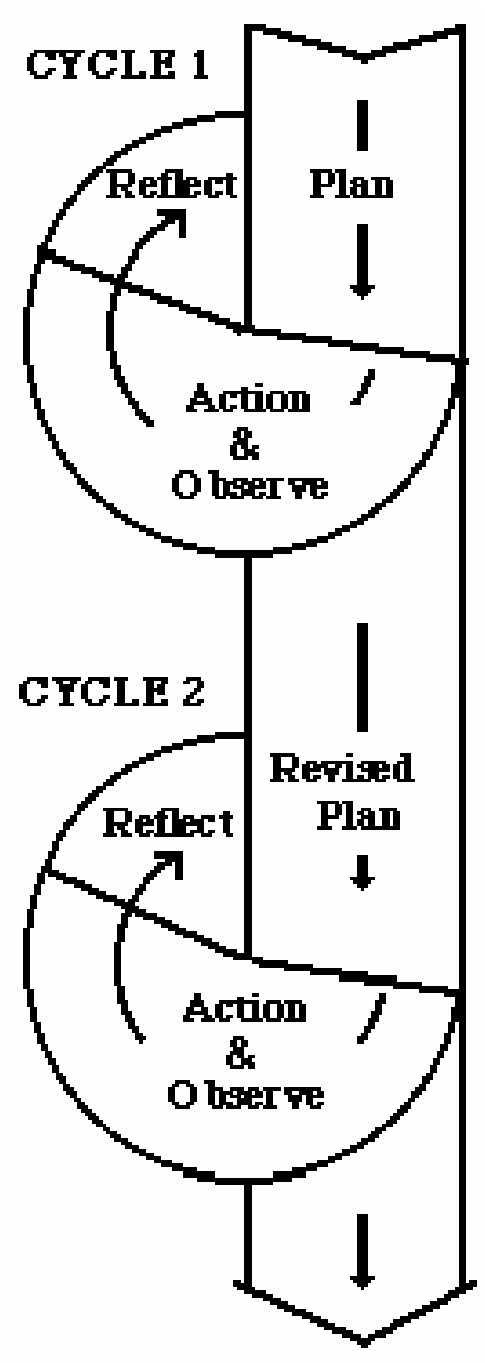

Figure 1: The Action Research Spiral

(Elden \& Chisholm, 1993)

\section{The Conceptual Model}

\section{Soft Systems Methodology}

Generally, problems can be classified into two different types, named "hard" and "soft" (Rapoport, 1970). A hard problem is structured and is more technologically oriented. On the contrary, a soft problem is unstructured and more socially or politically oriented. The soft systems methodology (SSM) was developed in the 1960s by Peter Checkland, Professor of Systems at Lancaster University. SSM originated by attempting to apply "hard" system engineering principles to tackle "soft" problems. It may be used to tackle any problem or situation which cannot be well defined. The basic idea of SSM leads to taking purposeful action in the situation.

SSM is a learning process which aims at improvement and tries to solve a complex and problematical human situation. It may be used to determine the source information which needs to support the planning activities for information and management problems. The distinctive feature of 
SSM is the application of action research in which the researcher also takes part in the development process. Bulow (1989) claimed that SSM is a methodology that aims to bring about improvement in areas of social concern by activating the people involved in a learning cycle which is ideally never ending. In other words, SSM is appropriate in complex and highly structured situations that are able to be well defined, particularly in terms of inputs and outputs. In summary, SSM is an evolving methodology that has been steadily developed into a systemic process of that is structured around a comparison between real-world problematic situations and conceptual models of relevant systems of purposeful activity.

\section{Education Programme Planning using Soft System Concepts}

In this paper, an education programme will be considered as a manufacturing system. Basically, a "system" may be defined literally as "a complex or organised whole; an assemblage or combination of things or parts forming a complex or unitary whole" (Hopkins, 1985). To be more precise, an education programme can be regarded as an integration of knowledge, techniques, and practices which are used for producing holistic students with depth of knowledge for further studies, employment, and personal interests. Normally, an education programme may have more than one objective specified by the responsible department. These objectives may not directly relate to one another but the overall objective of the programme is to develop an education programme. In this section, SSM is applied to establish a new methodology for designing an education programme. As described in the previous summary of SSM, the process is carried out and the results are stated in the following logical methodology.

The proposed logical methodology, named Soft Systems Programme Planning Methodology (SSPPM), consists of eight basic stages (Figure 2). Stage 1 perceives the environment of the programme planning and acquires the knowledge needed to carry out further analysis. Stages 2 and 3 perform analysis on the programme design issues from a social and an organisational viewpoint respectively. Programme design issues analysis addresses the issues raised in the programme design oriented approaches. The social and organisation analyses focus the analysis on social, cultural, political, and individual differences which the programme has to cater for. These two steps ensure that the new designed programme is both meeting the requirements and achieving the goal.

Stages 4 and 5 take care of different views of parties that include the school management, society needs, and departmental management in the design process. This is one of the strengths of this proposed methodology as it tries to look at the situation from different perspectives. Obviously different parties involved may have different limitations, expectations, and requirements to the new programme. By resolving this through the establishment of primary tasks or issue based root definitions, the perspectives of different parties can be considered or perhaps integrated.

Stages 6 and 7 focus on the comparison between the conceptual model and the reality and may generate a debate with the parties concerned in the final programme structure, such as horizontal and vertical linkage among different programme modules. These two steps ensure that the proposed programme. Stage 8 takes appropriate action to modify the proposed programme. It can be further refined to accurately reflect the needs and requirements of different parties. The results not only refine the new programme, but also strengthen the direction of changes required which are both feasible and desirable. When the conceptual model is developed and compared with the real-life situation, there is a range in the degree of possible changes that the designer can choose from. One important principle is that all participants need to negotiate in order to arrive at a feasible solution under the prevailing circumstance. 


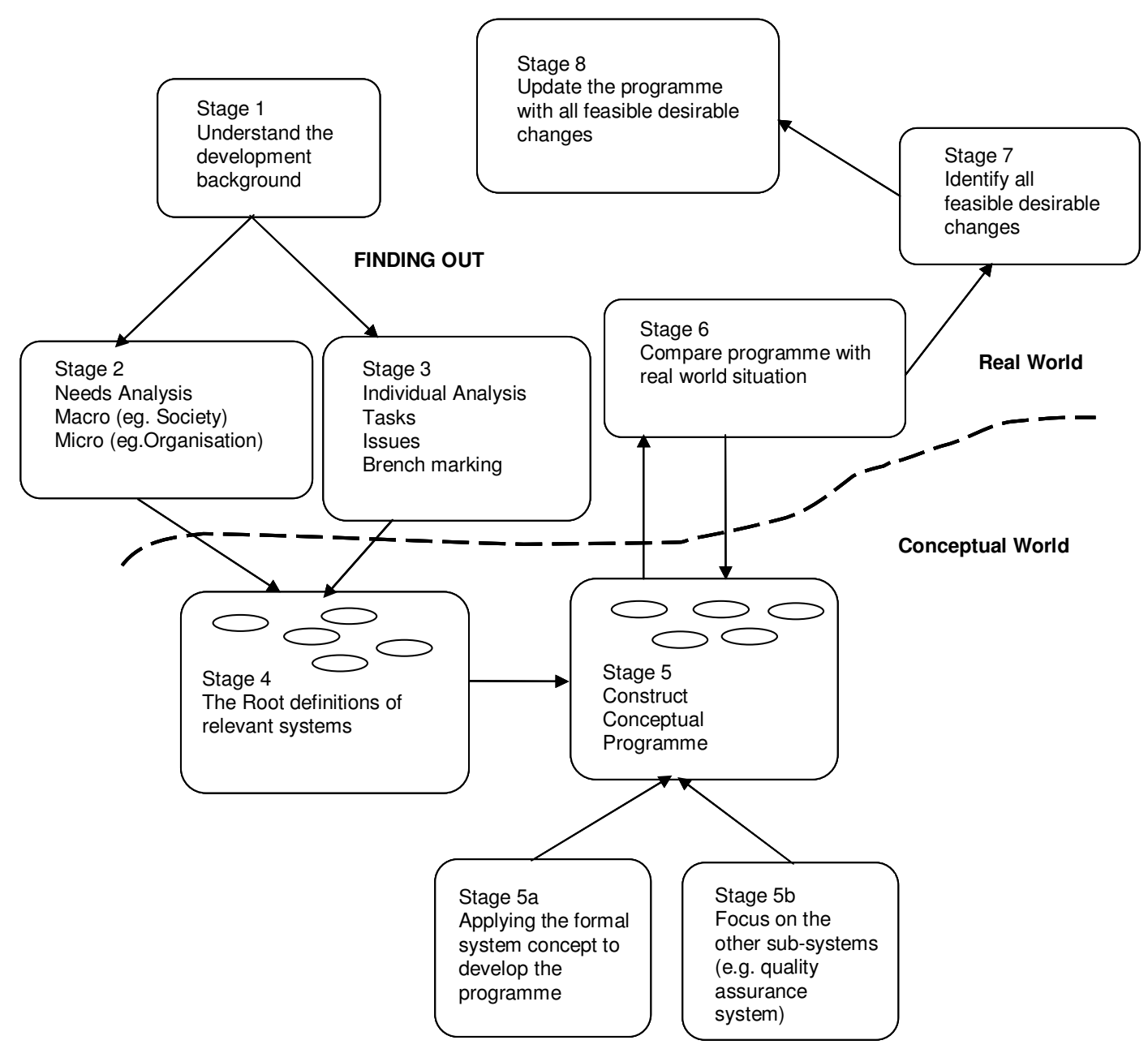

Figure 2: Soft Systems Programme Planning Methodology (SSPPM)

\section{A Case Study}

The case study examined the use of Soft Systems Programme Planning Methodology (SSPPM) to design a computing programme in Hong Kong. To make the case study successful, the research methodology must enable the researcher to be involved in a situation or a phenomenon in order to apply the theory and evaluate the worth and usefulness of that theory. Action research is adopted in this study because its primary focus is on solving real problems. Mostly, it is used in real situations, rather than in contrived, experimental studies.

The exploratory study was undertaken within a Computer Science Department of a mediumsized, private, post-secondary, catholic college, Zeta (a pseudonym). Zeta was established in 1985 and was founded on both professional and altruistic principles. This case study presents the development of the Associate of Science in Business Information Systems (hereafter AScBIS) programme in the Department of Computer Science of Zeta. The Department has 10 teaching staff graduating from various Computing majors, such as Computer Science and Information Systems. The AScBIS programme covers principle aspects of the specification, design, implementation, management, and assessment of Business Information systems. It also covers key theoretical, 
formal, and technical methods and principles appropriate to Information Systems. The steps to design the new AScBIS programme can be described as below:

\section{Stage 1:}

This step focuses on the study of IT development in Hong Kong. The application of IT/IS has been considered an important factor in maintaining Hong Kong's position as one of the world's leading financial and commercial centres. A Program Planning Committee (hereafter PPC) has been established to plan the new programme. The PPC has 15 experts with various academic backgrounds, such as Computer Science, Information Systems, Business Administration, and Language Studies. The researcher worked with the PPC to do the preliminary study. At the end of this stage, the PPC believes that there is a genuine need for graduates to possess the appropriate IT skills, a better understanding of general business knowledge, and the impact of IT on business organisations.

\section{Stage 2:}

This step focuses on studying the needs and requirements to develop AD courses in Hong Kong and, in particular, on Zeta's objective to develop AD programmes. At the end of this stage, the basic requirements of the AScBIS graduates have been identified. Some of them are shown below (Computer Science Department, 2002):

- able to apply for the up-to-date methodologies to solve IS-related problems using the knowledge of the current professional practices acquired;

- have sufficient knowledge for the hardware and software components of information systems;

- identify managerial/organizational needs;

- carry on a holistic personal development and learning using the generic knowledge and skills acquired;

- able to further their education at degree level and continue the process of lifelong learning.

\section{Stage 3:}

This step focuses on studying the needs and requirements to develop a BIS programme in Hong Kong and to identify goals for the new AScBIS programme. At the end of this stage, several important issues have been finalised. Some of them are shown below (Computer Science Department, 2002):

- identify an outline of all important aspects of the AScBIS programme;

- establish a systematic approach to manage the new Programme. It ensures that the AScBIS programme will be managed and delivered in a standard governed by the College's policy on quality assurance;

- identify all supporting resources, such as library. 


\section{Stage 4:}

This step focuses on studying the roles and responsibilities among different parties in the College. Several formal and informal meetings had been held in the department to collect comments and suggestions from different involved parties. The major finding from these meetings is that the new AScBIS programme course structure has to provide appropriate depth and breadth so as to allow progressive development of key skills and knowledge among the students. The PPC decides to streamline the constituent courses and identifies five key skills and knowledge:

- analysis, design and implementation of business information systems

- business environment and functions

- problem solving and programming languages

- data structure and database design

- computer systems components and networking infrastructure

\section{Stage 5:}

This step focuses on setting up the details of the AScBIS programme and identifies all supporting requirements. At the end of this stage, all issues of the new programme should be identified. In the discussion with the Programme Committee, a benchmarking exercise had been proposed. The findings of the exercise have fed useful input to the positioning of AScBIS vis-à-vis other AD programmes. A temporary structure of the Programme had been established at the end of this stage.

\section{Stages 6, 7, and 8}

These steps focus on the comparison between the conceptual model and the reality and make all feasibility changes. Several formal and informal meetings have been held during this stage to refine the contents of the programme. At the end of this stage, all issues of the new programme should be finalised. In summary, the new AScBIS programme is characterised by a combination of the following courses (Computer Science Department, 2002):

- Core Subjects: These subjects are the major elements of the Programme. They concern the generic concepts and basic techniques. Several hands-on practical sessions have been arranged to help students build up the computing skills.

- Guided Self-Study Subjects: These subjects are student-centred. The students have to take the initiative in problem discovery, analysis of alternative solutions and implementation.

- Soft Issues in Computing: These subjects focus on the non-technical issues which are profoundly important in the proper practice of IT, yet often neglected by the practitioners and variably absent from the typical or traditional Computer Science or Information Systems curricula.

The validation exercise conducted by the HKCAA for the AScBIS programme was completed on March 2002. The new programme was granted a conditional approval and was launched in September 2002. 


\section{Conclusion}

Business Information Systems has become an important programme in the Business discipline. The development of a new programme should not be done by an "adding-on" approach. We should consider all related information and limitations before the design of a new programme. SSPPM is not a completely new design model but an enhancement of "adding-on" approach by incorporating soft system theory to overcome subjective bias of human factors. An AScBIS curriculum developed from the conceptual model is expected to provide students with a better understanding of the relationship of different kinds of IT technology used in a Business environment, so they will be able to use the methodologies, techniques, and tools effectively in their future careers. In fact, the soft system concept and SSPPM model can be applicable to other disciplines.

\section{Acknowledgements}

The author would like to thank Dr. Chuk Yau for various insights concerning the ideas upon which this paper is built, and to the Mr. Wanbil Lee for his encouragement and support during the course of this research. Support from the Caritas Francis College is gratefully acknowledged. The anonymous referees and Miss Kelly McWilliam also made many valuable suggestions 


\section{References}

Avison, D., Lau, F., Myes, M., \& Nielsen, P. (1999). Action research. Communications of the ACM, 42 (1), 65-67.

Bulow, I.V. (1989). The bounding of problem situation and the concept of a systems boundary in soft systems methodology. Journal of Applied Systems Analysis, 16.

Checkland, P.B. \& Scholes, J. (2003). Soft systems methodology in action. USA: Wiley.

Computer Science Department. (2002). http://www.cfhc.caritas.edu.hk/college/main/en/academic/cs/cs_eng.htm

Elden M. \& Chisholm, R. F. (1993). Emerging varieties of action research: Introduction to the special issue. Human Relations, 46 (2).

Hong Kong Commerce, Industry and Technology Bureau. (2001). Retrieved from http://www.info.gov.hk/emb/eng/new/price.html

Hopkins, D. (1985). A teacher's guide to classroom research. Philadelphia, USA: Open University Press.

Johnson, R. A., Kast, F. E. \& Rosenzweig, J. E. (1964). Systems theory and management. Management Science, 10 (2).

Kemmis, S. (1980). Action research in retrospect and prospect. Annual meeting of the Australian Association for Research in Education, Sydney.

Lewin, K. (1946). Action research and minority problems. Journal of Social Issues, 2 (1).

Rapoport, R.N. (1970). Three dilemmas in action research. Human relations, 23.

Way forward mapped out to develop a skilled IT workforce. (2001, July 9). Hong Kong Commerce, Industry and Technology Bureau. Retrieved from http://www.info.gov.hk/citb/ctb/english/press/pr09072001.htm

Wilson, B. (1984). Systems: Concepts, methodologies and applications. USA: John Wiley.

\section{Biography}

Raymond Ho-Leung Tsoi is a Lecturer of Computer Science Department at the Caritas Francis Hsu College (Hong Kong). He holds a BSc in Electronic Engineering (National Taiwan Ocean University) and an MSc in Computer Science (University of Southwestern Louisiana). His research and consulting interests include software project management, human resources management, and IT Education. Mr. Tsoi is also a part-time PhD student of Griffith University. 